\title{
Promoção da saúde: ação necessária e urgente nas Américas
}

A América Latina e o Caribe (ALC) enfrentam uma acelerada transição demográfica que combina-se com um cenário epidemiológico complexo, onde convivem doenças transmissíveis que persistem, emergem e reemergem, com doenças crônicas não transmissíveis de carga crescente, além da elevada morbimortalidade por acidentes de trânsito e violências.

A resposta apropriada para situação tão desafiante exige, além do fortalecimento e da transformação dos sistemas de saúde para alcançar o efetivo acesso universal, a construção de uma agenda multissetorial que implemente políticas capazes de atuar nos seus principais determinantes sociais, econômicos e ambientais, promovendo a saúde.

A promoção da saúde foi reconhecida como um componente essencial dos sistemas de saúde desde a Declaração de Alma-Ata $(1978)^{1}$ em sua histórica defesa da saúde para todos e, a partir do movimento que desemboca na Carta de Ottawa $(1986)^{2}$ produz-se um nítido fortalecimento desse campo de práticas, incluindo sua maior presença na agenda da saúde global.

Entretanto, quando observamos os principais problemas de saúde pública na ALC, é inevitável reconhecer a necessidade de uma ação mais incisiva para promover a saúde da nossa população em todas as dimensões do quadro sanitário. A urbanização acelerada e sem políticas adequadas criou cidades em que a falta de acesso à água e ao saneamento coloca milhões de pessoas sob risco de epidemias de dengue, zika e chikungunya. $\mathrm{O}$ tabaco ainda responde por dezenas de milhares de mortes que poderiam ser evitadas com a adoção de medidas legislativas e regulatórias, como o Brasil e outros países têm, exitosamente, implantado. O crescimento do sobrepeso e da obesidade exige que avancemos com mais rapidez na adoção de ações que favoreçam a opção pela alimentação saudável, como a etiquetagem frontal que alerte o consumidor sobre altos teores de sódio, açúcar ou gordura, já estabelecida no Chile e em discussão por outros países. Os números assustadores dos mortos e acidentados graves por acidentes de trânsito podem ser reduzidos com a adoção de medidas como a obrigatoriedade do cinto em todos os assentos, capacetes para motociclistas, proibição do uso de bebidas alcoólicas pelos condutores, redutores de velocidade e outras intervenções que salvam vidas.

A OPAS está adotando, este ano, uma nova estratégia e plano de ação sobre a promoção da saúde enfatizando a necessidade urgente da adoção dessas e de outras políticas, baseadas em evidências, e fundamentais para garantir o direito à saúde da população das Américas.

Jarbas Barbosa da Silva Júnior (https://orcid.org/0000-0002-3078-9642) ${ }^{1}$

${ }^{1}$ Organização Pan-Americana de Saúde (OPAS/OMS). Washington EUA.

\section{Referências}

1. Organização Mundial da Saúde (OMS). Declaración de Alma-Ata [Internet]. Conferência Internacional sobre Atenção Primária da Saúde, 6 a 12 de setembro de 1978, Alma-Ata, URSS. Genebra: OMS; 1978 [acessado 2019 Set 1]. Disponível em: https:// apps.who.int/iris/bitstream/handle/10665/39244/9243541358.pdf;jsessionid=2 8EACFD5F04427A003615B798EAF3C1C?sequence $=1$.

2. Organização Mundial da Saúde (OMS). Carta de Ottawa para la Promoción de la Salud. Primeira Conferência Internacional sobre Promoção da Saúde [Internet]. 21 de novembro de 1986; Ottawa, Ontário, Canadá. Genebra: OMS; 1986 [acessado 2019 Set 1]. Disponível em: http://www1.paho.org/spanish/hpp/ottawachartersp.pdf?ua=1.

3. Organização Pan-Americana de Saúde (OPAS). Estratégia e plano de ação para a promoção da saúde no contexto dos Objetivos de Desenvolvimento Sustentável 2019-2030. Washington: OPAS; 2019 [acessado 2019 Set 1]. Disponível em: https://www. paho.org/hq/index.php?option=com_docman\&view=download\&alias=49689-cd57-10-p-promocao-saude\&category_slu$\mathrm{g}=\mathrm{cd} 57$-pt\&Itemid=270\&lang $=\mathrm{pt}$ 